\title{
Facile Tuning of the Surface Energy of Cellulose Nanofibers for Nanocomposite Reinforcement
}

\author{
Alireza Hosseinmardi, ${ }^{\circledR}$ Pratheep Kumar Annamalai, ${ }^{\circledR}$ Benoit Martine, Jordan Pennells, \\ Darren J. Martin,* and Nasim Amiralian*(1)
}

Australian Institute for Bioengineering and Nanotechnology (AIBN), The University of Queensland, Brisbane 4072, Queensland, Australia
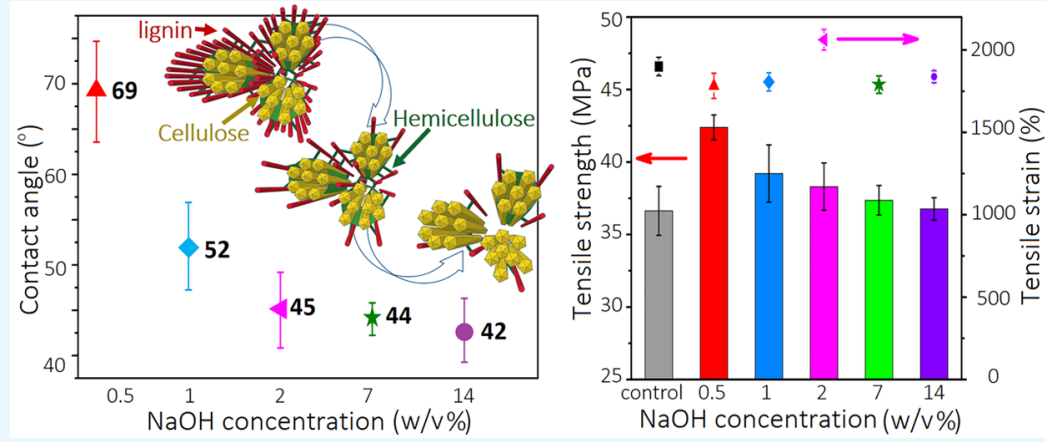

ABSTRACT: The isolation of nanocellulose from lignocellulosic biomass, with desirable surface chemistry and morphology, has gained extensive scientific attention for various applications including polymer nanocomposite reinforcement. Additionally, environmental and economic concerns have driven researchers to explore viable alternatives to current isolation approaches, employing chemicals with reduced environmental impact. To address these issues, in this study, we have tuned the amphiphilic behavior of cellulose nanofibers (CNFs) by employing controlled alkali treatment, instead of in combination with expensive, environmentally unsustainable conventional approaches. Microscopic and spectroscopic analysis demonstrated that this approach is capable of tuning composition and interfacial tension of CNFs through a careful control of the quantity of residual lignin and hemicellulose. To elucidate the performance of CNF as an efficient reinforcing nanofiller in hydrophobic polymer matrices, prevulcanized natural rubber (NR) latex was employed as a suitable host polymer. CNF/NR nanocomposites with different CNF loading levels $(0.1-1$ wt \% CNF) were prepared by a casting method. It was found that the incorporation of 0.1 wt \% CNF treated with a $0.5 \mathrm{w} / \mathrm{v} \%$ sodium hydroxide solution led to the highest latex reinforcement efficiency, with an enhancement in tensile stress and toughness of $16 \%$ to $42 \mathrm{MPa}$ and $9 \%$ to $197 \mathrm{MJ} \mathrm{m}^{-3}$, respectively. This property profile offers a potential application for the high-performance medical devices such as condoms and gloves.

\section{INTRODUCTION}

Cellulose, as the main component of lignocellulosic biomass (e.g., wood, grass, and agricultural residue), has gained wide attention for its advantageous attributes, which include its abundance, biodegradability, low cost, and sustainability. Therefore, it has increasingly been used in advanced applications such as biomedicine, energy storage, cosmetics, and nanocomposites. ${ }^{1-5}$ However, isolation of nanocellulose with desirable morphology and structure, such as cellulose nanocrystals or cellulose nanofibers (CNFs), along with practical surface chemistry typically entails chemical pretreatments and/or further chemical modifications, which can be expensive and cause several environmental issues. ${ }^{6-9}$ Therefore, efficient and environmentally friendly CNF production processes that are associated with a reduction in total mechanical energy, water, and chemical consumption, together with the isolation of consistently high aspect ratio CNF, are needed in order to produce more cost-effective and sustainable nanocellulose materials.

Lignocellulosic biomass consists mainly of cellulose, along with lignin, hemicellulose, and extractives (resins, wax, fatty acids, etc.), with these components tightly interwoven within the cell wall. Residual lignin and hemicellulose, as more hydrophobic materials compared to cellulose, could decrease the polarity of the nanocellulose system and confer interesting properties to enhance the performance of nanocellulose material (especially for large-scale production and dispersion in hydrophobic matrices). ${ }^{2,10-12}$ However, most conventional lignocellulose treatments produce predominantly hemicellulose and lignin-free fibers, leading to stiffer and more hydrophilic CNF (see the Supporting Information). Therefore,

Received: August 20, 2018

Accepted: October 24, 2018

Published: November 27, 2018 


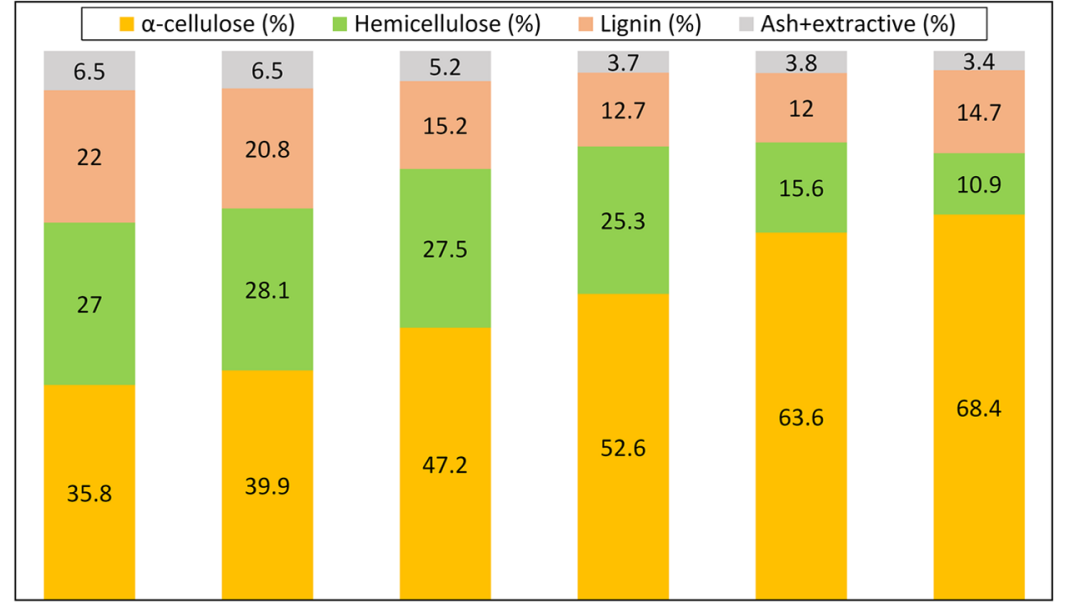

Water-washed $0.5 \mathrm{w} / \mathrm{v} \% \mathrm{NaOH} \quad 1 \mathrm{w} / \mathrm{v} \% \mathrm{NaOH} \quad 2 \mathrm{w} / \mathrm{v} \% \mathrm{NaOH} \quad 7 \mathrm{w} / \mathrm{v} \% \mathrm{NaOH} \quad 14 \mathrm{w} / \mathrm{v} \% \mathrm{NaOH}$

Figure 1. Relative biochemical composition (cellulose, lignin, hemicellulose, ash, and extractives) of water-washed and alkali-treated T. pungens with different concentrations of sodium hydroxide.

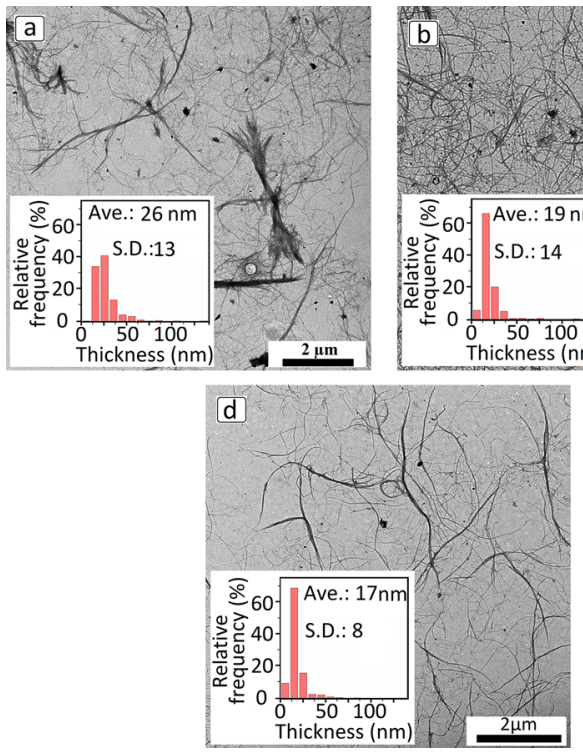

Figure 2. TEM images of the CNF series (a) $0.5 \mathrm{w} / \mathrm{v} \% \mathrm{NaOH}-\mathrm{CNF}$ $\mathrm{NaOH}-\mathrm{CNF}$, and (e) $14 \mathrm{w} / \mathrm{v} \% \mathrm{NaOH}-\mathrm{CNF}$ (the scale bar is $2 \mu \mathrm{m}$ ).

treatment of lignocellulose biomass with sodium hydroxide, which is industrially known as the delignification process, not only enables tuning of the residual hemicellulose and lignin content within the nanocellulose composition but also increases fiber swelling, making the fibrillation process simpler, cheaper, less energy-intensive, and more environmentally sustainable. ${ }^{2,8}$ However, although sodium hydroxide is commonly used as a pretreatment process for biomass, only a few studies exclusively employed alkali treatment to process lignocellulosic biomass ${ }^{13-16}$ and rarely prepared CNF. ${ }^{8,17}$ On the basis of our knowledge, there is no study on the influence of controlled alkali treatment performed at such a low concentration (lower than $2 \mathrm{w} / \mathrm{v} \% \mathrm{NaOH}$ ) on the physical, chemical, and thermal properties of the fibrillated CNF.

We have already demonstrated the effect of nanofiber surface chemistry on the reinforcement efficiency of the natural rubber (NR) latex, concluding that interfacial adhesion between CNF and NR can be enhanced by adjusting the surface chemistry of CNF. ${ }^{18}$ The aim of this study is to illuminate the influence of controlled alkali treatments, ranging from very mild to aggressive, on the composition of spinifex grass (rarely addressed before) and subsequently investigate the characteristics and performance of the spinifex-derived CNF series as reinforcement nanofillers in the NR latex (to demonstrate the practicality of alkali treatment to prepare $\mathrm{CNF}$ for various applications). The results from this systematic evaluation successfully demonstrated that using different concentrations of sodium hydroxide during the treatment is an effective approach to engineer and tune the composition and surface chemistry of isolated CNF. Therefore, this method showed potential to be used as an environmentally sustainable and cost-effective approach for CNF production from lignocellulosic biomass with a desirable surface chemistry (from hydrophobic to hydrophilic surface tension), instead of using conventional, more aggressive, and toxic oxidizing agents for pulping. 


\section{RESULTS AND DISCUSSION}

CNF with Different Compositions and Morphologies. The biochemical composition (glucan, hemicellulose including, xylan, arabinan, mannan, both Klason lignin and acidsoluble lignin, ash, and extractives) of water-washed Triodia pungens and treated T. pungens is shown in Figure 1 [Table S1 lists detailed biochemical composition (glucan, xylan, arabinan, mannan, Klason lignin- and acid-soluble lignin, ash, and extractives)]. The fraction of total sugar was increased when using a higher concentration of sodium hydroxide during the alkali treatment. The ratio of $\alpha$-cellulose increased from 35.8 to $68.4 \%$ for water-washed T. pungens and $14 \mathrm{w} / \mathrm{v} \% \mathrm{NaOH}-$ treated grass, respectively. This result confirmed that the application of an aggressive alkali treatment alone is capable of producing a comparable cellulose-rich product from spinifex biomass.

The content of hemicellulose decreased by increasing the concentration of sodium hydroxide from $0.5 \mathrm{w} / \mathrm{v} \% \mathrm{NaOH}$ (28.1\% hemicellulose) to $14 \mathrm{w} / \mathrm{v} \% \mathrm{NaOH}$ (10.9\% hemicellulose). The fraction of lignin also decreased when it was treated with $0.5 \mathrm{w} / \mathrm{v} \% \mathrm{NaOH}$ (up to $7 \mathrm{w} / \mathrm{v} \% \mathrm{NaOH}$ solution); this occurs through cleavage reactions where hydroxide anions $\left(\mathrm{OH}^{-}\right)$break $\alpha$-aryl ether and $\beta$-aryl ether linkages, splitting lignin macromolecules into small fragments that can be dissolved in the aqueous alkali media. ${ }^{19}$ On the other hand, the high alkali concentration was capable of producing water-soluble ingredients by hydrolyzing the hemicellulose components and partially decomposing the intra- and intermolecular hydrogen bonds. ${ }^{20,21}$ The content of Klason lignin increased to $13.6 \%$ when grass was treated with a $14 \mathrm{w} / \mathrm{v} \% \mathrm{NaOH}$ solution, which could be associated with the condensation of lignin or formation of lignincarbohydrate complexes on the surface of remaining polysaccharides during the alkali treatment. ${ }^{22,23}$ In addition, scanning electron microscopy (SEM) images of samples in Figure S2 illustrate that by increasing the sodium hydroxide concentration, cell wall, xylem vessel, lignin, extractives, and ash were further removed from the cell structure. Therefore, thick and interwoven structures transformed into a loose lignocellulosic matrix, ready to be further nanofibrillated with the assistance of high-pressure homogenization $(\mathrm{HPH})$.

The diameter distribution and structure of the CNF samples were characterized by transmission electron microscopy (TEM) images (Figure 2a-e). These observations confirm the success of CNF refinement, even with very mild alkali treatment (only $0.5 \mathrm{w} / \mathrm{v} \%$ ), whereas the yield of CNF from water-washed $T$. pungens was not practical. The average diameters of $0.5 \mathrm{w} / \mathrm{v} \% \mathrm{NaOH}-\mathrm{CNF}, 1 \mathrm{w} / \mathrm{v} \% \mathrm{NaOH}-$ $\mathrm{CNF}, 2 \mathrm{w} / \mathrm{v} \% \mathrm{NaOH}-\mathrm{CNF}, 7 \mathrm{w} / \mathrm{v} \% \mathrm{NaOH}-\mathrm{CNF}$, and 14 $\mathrm{w} / \mathrm{v} \% \mathrm{NaOH}-\mathrm{CNF}$ were $26 \pm 13,19 \pm 14,14 \pm 9,26 \pm 13$, $17 \pm 8$, and $19 \pm 12 \mathrm{~nm}$, respectively. The average CNF diameter decreased by increasing the concentration of sodium hydroxide from 0.5 to $2 \mathrm{w} / \mathrm{v} \%$ because of the decrease in lignin content from $20.8 \%$ (in $0.5 \mathrm{w} / \mathrm{v} \% \mathrm{NaOH}$ ) to $12.7 \%$ (in $2 \mathrm{w} / \mathrm{v} \% \mathrm{NaOH}$ ) and cleavage on the cell surface as observed in SEM images (Figure S1). However, using a higher sodium hydroxide concentration in alkali treatment (7 and $14 \mathrm{w} / \mathrm{v} \%$ ) led to increase the level of CNF agglomeration. This is due to the further removal of hemicellulose and lignin components, increasing the content of $\alpha$-cellulose, which raises the density of hydroxyl groups on the CNF surface and increased affinity of CNF interaction.
X-ray diffraction (XRD) analysis was conducted to interpret the changes in structural and crystalline features of CNF samples with different concentrations of sodium hydroxide treatment. Figure 3a,b shows diffractograms of extracted CNF

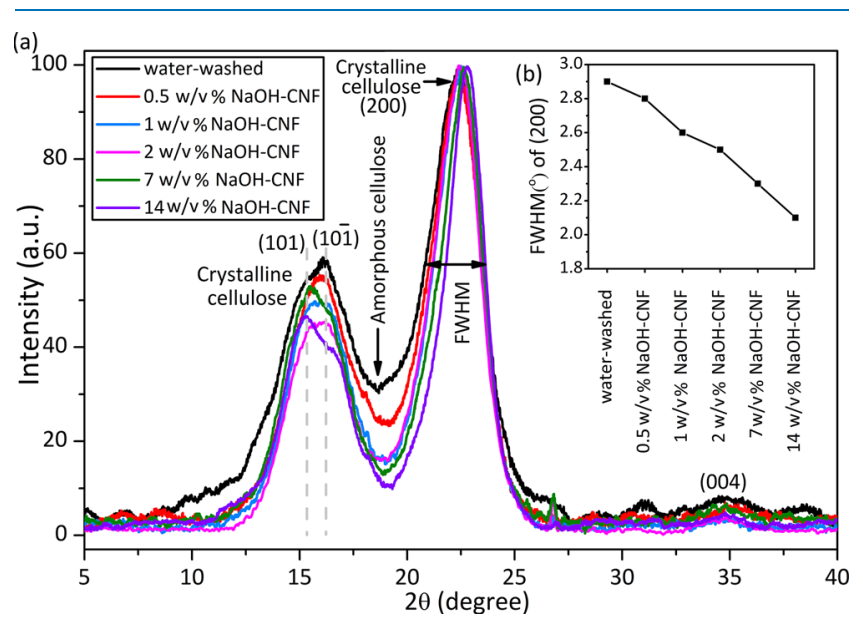

Figure 3. (a) XRD curves and (b) FWHM of (200) of water-washed and treated T. pungens samples $(0.5 \mathrm{w} / \mathrm{v} \% \mathrm{NaOH}-\mathrm{CNF}, 1 \mathrm{w} / \mathrm{v} \%$ $\mathrm{NaOH}-\mathrm{CNF}, 2 \mathrm{w} / \mathrm{v} \% \mathrm{NaOH}-\mathrm{CNF}, 7 \mathrm{w} / \mathrm{v} \% \mathrm{NaOH}-\mathrm{CNF}$, and 14 $\mathrm{w} / \mathrm{v} \% \mathrm{NaOH}-\mathrm{CNF}$ ).

and full width at half-maximum (FWHM) of the cellulosic crystalline peak at approximately $22^{\circ}$, respectively. The semicrystalline XRD patterns displayed a combination of crystalline peaks with a broad amorphous hump. Well-defined crystalline cellulose I peaks can be seen at $2 \theta=15.2^{\circ}, 16.2^{\circ}$, $22.3^{\circ}$, and $34.5^{\circ}$, which correspond to (101), (10 $\left.\overline{1}\right),(200)$, and (004) planes, respectively. ${ }^{24,25}$ Increasing the sodium hydroxide concentration from 7 to $14 \mathrm{w} / \mathrm{v} \%$ resulted in decreasing the intensity of the $(10 \overline{1})$ plane, clarifying that alkali treatment has an impact on crystalline cellulose orientation. ${ }^{26}$ On the other hand, the amorphous phase (disordered region) is approximately at $2 \theta=18.5^{\circ}$. As expected, the intensity of the amorphous phase decreased upon increasing the sodium hydroxide concentration and removal of amorphous hemicellulose and lignin, as shown in Figure 1. ${ }^{26,27}$

Figure $3 \mathrm{~b}$ illustrates how FWHM of the cellulose crystalline peaks decreased with increasing concentration of sodium hydroxide during the alkali treatment. On the basis of the Debye-Scherrer equation, the mean size of the ordered (crystalline) region has an inverse relationship with the FWHM. ${ }^{17,28}$ Therefore, the crystalline cellulosic domain increased upon treatment with a higher sodium hydroxide concentration. In other words, concentrated sodium hydroxide could effectively remove the noncellulosic amorphous polysaccharides. $^{24,26}$

The Fourier transform infrared (FT-IR) spectra of waterwashed and treated samples showed clear changes in the lignocellulosic chemical composition after the alkali treatments (see Figure S2 and Table S2). The relative intensities of absorption bands at $833 \mathrm{~cm}^{-1}$ (bending aromatic $\mathrm{C}-\mathrm{H}$ out of plane deformation), $1237 \mathrm{~cm}^{-1}$ (aromatic ring breathing of C$\mathrm{O}$ and stretching of $\mathrm{C}-\mathrm{O}$ in syringyl or guaicyl ring), and 1730 $\mathrm{cm}^{-1}$ (stretching of $\mathrm{C}=\mathrm{O}$, ester-link acetyl, $p$-coumaroyl, and feruloyl groups between lignin and hemicellulose) decreased. ${ }^{29,30}$ In addition, the band at $2846 \mathrm{~cm}^{-1}$ assigned to $\mathrm{C}-\mathrm{H}$ symmetrical stretching, ${ }^{31}$ and band at $2920 \mathrm{~cm}^{-1}$ associated with the symmetric $\mathrm{C}-\mathrm{H}$ stretching absorption 
bond in aromatic methoxyl, methyl, and methylene groups ${ }^{32}$ or $\mathrm{C}-\mathrm{H}_{2}$ asymmetric stretching, ${ }^{33}$ became less intense with increasing the sodium hydroxide concentration. The disappearance of these peaks by increasing the concentration of sodium hydroxide indicated the removal of hemicellulose and lignin components from $T$. pungens samples, which is in agreement with the sugar analysis results. ${ }^{34}$

Figure 4 shows the one-dimensional cross-polarization/ magic-angle spinning (CP/MAS) ${ }^{13} \mathrm{C}$ NMR spectra of the

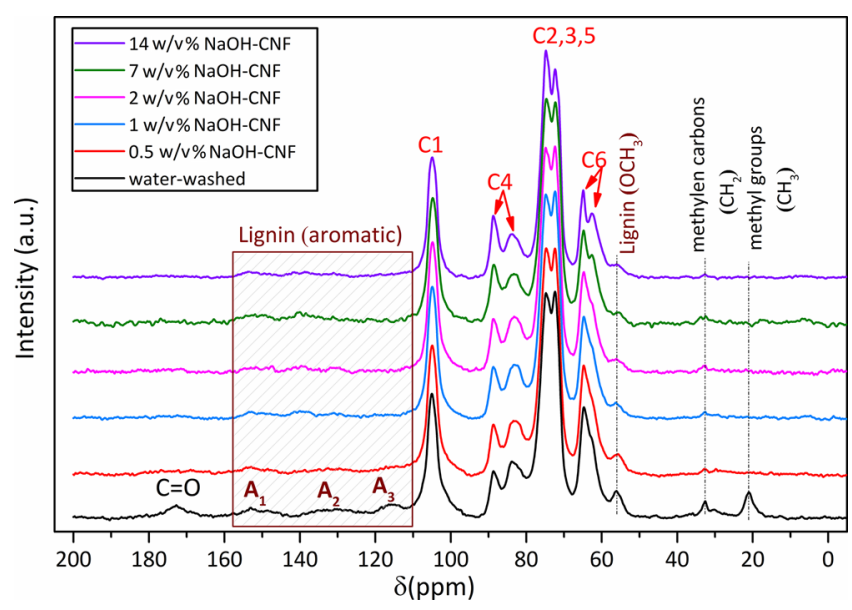

Figure 4. Solid-state ${ }^{13} \mathrm{C} \mathrm{CP} / \mathrm{MAS}$ NMR spectra of water-washed and treated T. pungens $(0.5 \mathrm{w} / \mathrm{v} \% \mathrm{NaOH}-\mathrm{CNF}, 1 \mathrm{w} / \mathrm{v} \% \mathrm{NaOH}-\mathrm{CNF}$, $2 \mathrm{w} / \mathrm{v} \% \mathrm{NaOH}-\mathrm{CNF}, 7 \mathrm{w} / \mathrm{v} \% \mathrm{NaOH}-\mathrm{CNF}$, and $14 \mathrm{w} / \mathrm{v} \%$ $\mathrm{NaOH}-\mathrm{CNF}$ ).

water-washed T. pungens and the CNF samples. The ${ }^{13} \mathrm{C}$ solidstate NMR spectra of lignocellulosic materials can be divided into three regions. The region up to $60 \mathrm{ppm}$ is dedicated to aliphatic structures, the central region between 60 and 110 $\mathrm{ppm}$ is related to the cellulosic polysaccharide (carbons of carbohydrate), and the last region over $110 \mathrm{ppm}$ (especially the region between 110 and $160 \mathrm{ppm}$ ) is characterized by carbons in aromatic lignin. ${ }^{35-37}$ For the water-washed $T$. pungens spectrum, signals at 21.2, 32.6, and $56.1 \mathrm{ppm}$ are attributed to the acetate methyl groups $\left(\mathrm{CH}_{3}\right)$, methylene carbon $\left(\mathrm{CH}_{3}\right)$, and the methoxyl groups $\left(\mathrm{OCH}_{3}\right)$, respectively, which are present in the xylan and lignin components. ${ }^{37}$ By increasing the concentration of sodium hydroxide during alkali treatment, the intensity of these peaks was significantly reduced, which confirmed the depletion of hemicellulose and lignin compared to water-washed T. pungens.

The central region of ${ }^{13} \mathrm{C}$ solid-state NMR is attributed to the cellulosic polysaccharide, and the individual resonances of carbon atoms in the $\beta$-D-glucose monomer are assigned to $\mathrm{C} 1$ and C6, as illustrated in Figure S3. The signal assigned to $\mathrm{C} 1$ is at $105 \mathrm{ppm}$, whereas $\mathrm{C} 2$ and $\mathrm{C} 3$ with $\mathrm{C} 5$ produce a broad band with two peaks at 72.3 and 74.7 ppm, respectively. C4 and C6 are composed of two peaks, which are associated with crystalline and amorphous cellulose, respectively. The signals at 83.8 and $62.5 \mathrm{ppm}$ are attributed to the amorphous cellulose (crystal surfaces or disordered cellulose) in C4 and C6, respectively. Furthermore, peaks at 64.7 and $88.6 \mathrm{ppm}$ are attributed to crystalline cellulose in $\mathrm{C} 6$ and $\mathrm{C} 4$, respectively. ${ }^{38-40}$ Study of ${ }^{13} \mathrm{C}$ solid-state NMR from lignocellulosic biomass is a useful tool to estimate the proportion of crystalline and amorphous regions within a cellulose sample. $\mathrm{C} 4$ and $\mathrm{C} 6$ can be fitted into a broad signal and a narrow signal, which correspond to the amorphous and crystalline cellulose, respectively. ${ }^{41}$ It determined that by increasing the concentration of sodium hydroxide during alkali treatment, the ratio of crystalline cellulose relative to amorphous cellulose was increased (see Figures S4 and S5). In other words, treatment with a higher concentration of sodium hydroxide increased the degree of crystallinity of CNF, which is in agreement with the $\mathrm{XRD}$ results and the previous study by Sun et al. ${ }^{38}$

In addition, Figures 4 and S5 show a broad signal of C6 for water-washed $T$. pungens and CNF produced after treatment with a low concentration of sodium hydroxide (Figure S5a-d), whereas the signal of $\mathrm{C} 6$ was divided into two distinct peaks for 7 and $14 \mathrm{w} / \mathrm{v} \% \mathrm{NaOH}-\mathrm{CNF}$ (Figure S5e,f). This phenomenon can be explained by the resonance overlap of xylan, as the most prevalent noncellulose polysaccharide, and C6 in the cellulose structure. The chemical shift of carbon-5 in the xylan (see the hemicellulose unit structure in Figure S3) is at $63.3 \mathrm{ppm},{ }^{35}$ and the disappearance of this signal from solidstate NMR justifies the removal of hemicellulose during aggressive alkali treatment, which is in agreement with previously discussed biochemical composition results. Furthermore, the signal assigned to the carbon- 4 in hemicellulose appeared around $81 \mathrm{ppm}$ in the water-washed T. pungens but faded after treatment. This characterized signal is the consequence of cellulose and xylan interaction and agglomeration, which can be seen when hemicellulose and methyl moieties associate with acetyl groups, generating signals at $\sim 172$ and 21.2 ppm. $^{35,42,43}$ These signals are only available in the spectra of water-washed $T$. pungens and are significantly reduced after treatment, which highlights the decomposition of connections between acetyl groups and hemicellulose. ${ }^{37}$

The region around $110 \mathrm{ppm}$ indicates signals assigned to aromatic amino acid structures that exist within lignin components. ${ }^{44}$ Lignin, as a macromolecular biopolymer, is derived from dehydrogenative polymerization of phenylpropane units, including syringyl (synapsyl alcohol), guaiacyl (coniferyl alcohol), and $p$-hydroxyphenyl ( $p$-coumaryl alcohol). ${ }^{45,46}$ Resonance of carbons in these structures generates three signals in the solid-state ${ }^{13} \mathrm{C} \mathrm{CP} / \mathrm{MAS} \mathrm{NMR}$ spectra, which are labeled A1, A2, and A3 in the chemical shift of these peaks $\left(\delta_{\mathrm{C}}\right)$, and corresponding carbons are listed and plotted in Table S3 and Figure S6, respectively. ${ }^{47}$ Integration of the area between 110 and $160 \mathrm{ppm}$ gives a ratio of the number of carbon in lignin structures that initiate resonance. ${ }^{48}$ Figure S6 shows this value for all samples, such that the integrated value decreased by increasing the sodium hydroxide concentration during alkali treatment. This is caused by the more efficient removal of lignin from the $T$. pungens structure when using concentrated alkali hydroxide, which is in agreement with the previously discussed results.

Surface Properties of CNF. The X-ray photoelectron spectroscopy (XPS) survey scan and C 1s high-resolution XPS spectra of water-washed and treated $T$. pungens CNF samples are shown in Table S4 and Figure 5a-f, respectively. Carbon and oxygen were the predominant surface elements (about $97 \%$ ), with traces of silicon, nitrogen, and calcium detected as being taken up by the grass root from the soil. ${ }^{49-51}$ The presence of fluorine can be attributed to the sample preparation method, where samples were dried between two Teflon sheets under pressure. The high-resolution carbon spectra were fitted based on previously published papers [C $1 \mathrm{~s}$ was fitted by $\mathrm{C} 1(\mathrm{C}-\mathrm{C}, \mathrm{C}-\mathrm{H}), \mathrm{C} 2(\mathrm{C}-\mathrm{O}$, used as a reference peak at $286.73 \mathrm{eV}$ and all $\mathrm{C} 1 \mathrm{~s}$ charge shifts were corrected 

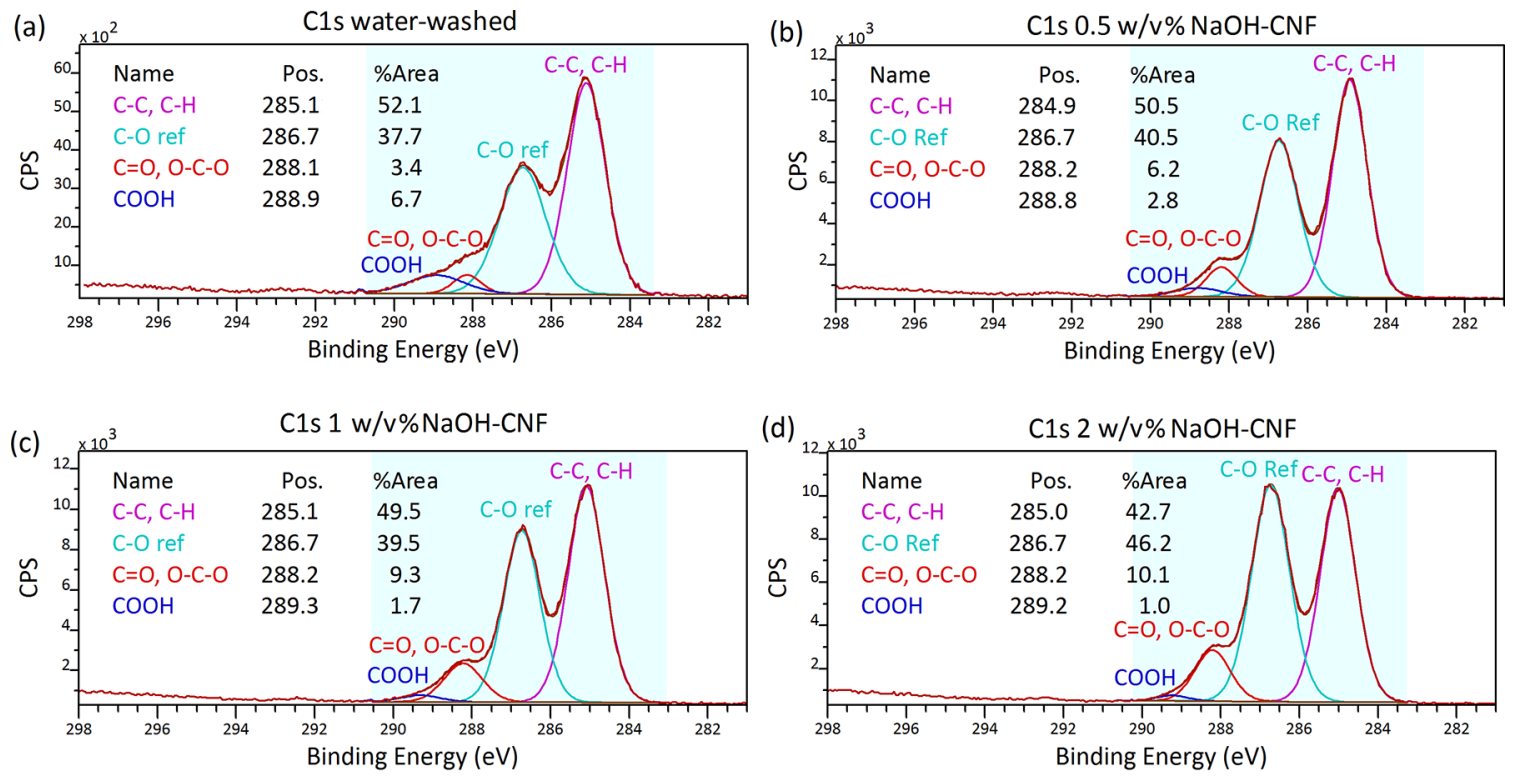

(d)
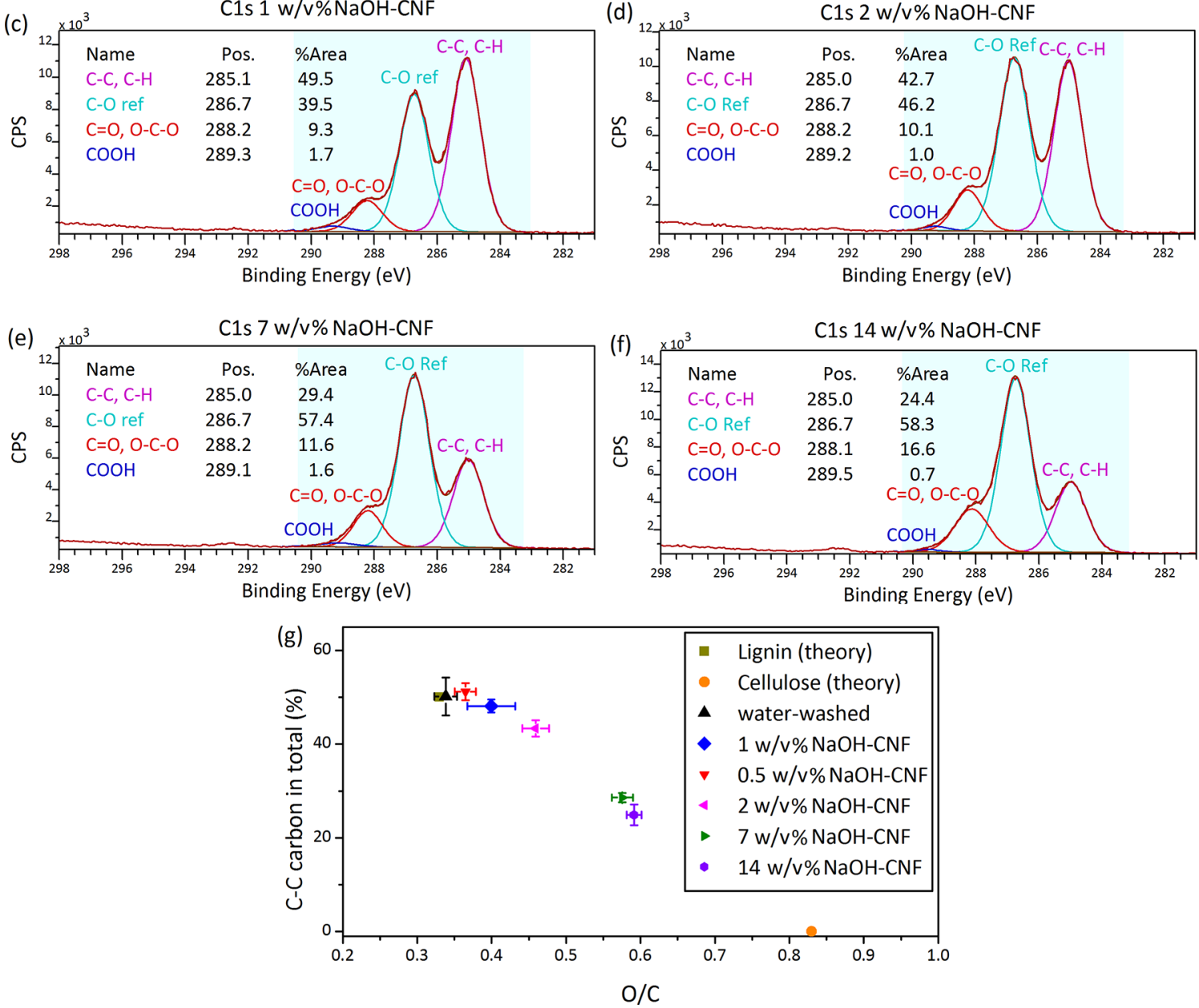

Figure 5. High-resolution carbon C 1s XPS spectra for (a) water-washed and treated T. pungens at various sodium hydroxide concentrations: (b) $0.5 \mathrm{w} / \mathrm{v} \% \mathrm{NaOH}-\mathrm{CNF}$, (c) $1 \mathrm{w} / \mathrm{v} \% \mathrm{NaOH}-\mathrm{CNF}$, (d) $2 \mathrm{w} / \mathrm{v} \% \mathrm{NaOH}-\mathrm{CNF}$, (e) $7 \mathrm{w} / \mathrm{v} \% \mathrm{NaOH}-\mathrm{CNF}$, and (f) $14 \mathrm{w} / \mathrm{v} \% \mathrm{NaOH}-\mathrm{CNF}$. (g) Correlation plot showing the percentage of $\mathrm{C}-\mathrm{C}$ components in samples vs the $\mathrm{O} / \mathrm{C}$ ratio of cellulose (calculated based on the presented value in Table S4), lignin, water-washed, and treated T. pungens samples.

based on $\mathrm{C} 2$ bonding position), $\mathrm{C} 3(\mathrm{C}=\mathrm{O}$ and $\mathrm{O}=\mathrm{C}-\mathrm{O})$, and $\mathrm{C} 4(\mathrm{COOH})]^{18,52}$ As shown in Figure 5a, the intensity of $\mathrm{C} 1$ for the water-washed $T$. pungens is $52 \%$, whereas increasing the concentration of sodium hydroxide from 0.5 to $14 \mathrm{w} / \mathrm{v} \%$ continually decreased the intensity of $\mathrm{C} 1$ to $24 \%$ for $14 \mathrm{w} / \mathrm{v} \%$ $\mathrm{NaOH}-\mathrm{CNF}$ (Figure 5f). C1 represents aliphatic and aromatic carbon backbones, and in theory, cellulose with polysaccharide composition does not include $\mathrm{C} 1 .^{53}$ Therefore, aggressive alkali treatment removes more lignin, adventitious carbon, and extractives (such as resins and fatty acids). ${ }^{54}$ On the other hand, the intensity of $\mathrm{C} 2$, which is present in pure cellulose, was increased by using a higher concentration of sodium hydroxide for alkali treatment. For instance, the intensity of C2 in water-washed T. pungens and $14 \mathrm{w} / \mathrm{v} \%$ $\mathrm{NaOH}-\mathrm{CNF}$ is 37 and $58 \%$, respectively.

Figure $5 \mathrm{~g}$ shows that increasing the concentration of sodium hydroxide from 0.5 to $14 \mathrm{w} / \mathrm{v} \%$ results in CNF transitioning from a lignin-like structure (in theory, the $\mathrm{O} / \mathrm{C}$ ratio vs $\mathrm{C} 1$ for lignin is 0.33 vs 0.5 ) to a cellulose-rich structure (in theory, the $\mathrm{O} / \mathrm{C}$ ratio vs $\mathrm{C} 1$ for pure cellulose is 0.83 vs 0$).{ }^{55}$

The water contact angle measurement was employed to characterize the surface tension and evaluate the hydrophilic/ hydrophobic properties of CNF nanopaper samples, as shown in Figure 6. This study showed that nanopapers made of 0.5 $\mathrm{w} / \mathrm{v} \% \mathrm{NaOH}-\mathrm{CNF}$ presented the highest contact angle value with $69^{\circ}$, as a consequence of the higher content of lignin and hemicellulose compared to other samples [as discussed in 


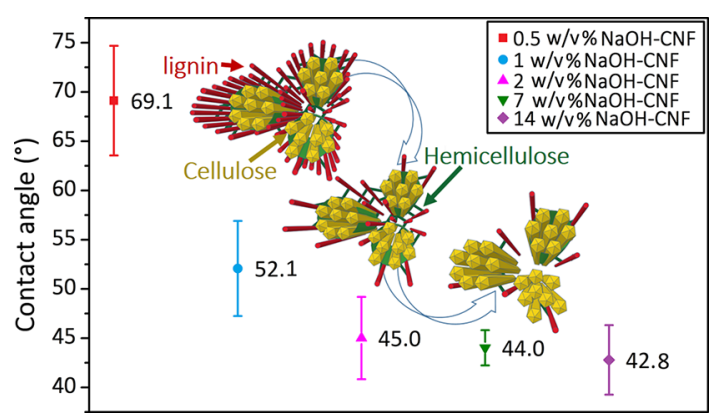

Figure 6. Water contact angle values for the CNF series $(0.5 \mathrm{w} / \mathrm{v} \%$ $\mathrm{NaOH}-\mathrm{CNF}, 1 \mathrm{w} / \mathrm{v} \% \mathrm{NaOH}-\mathrm{CNF}, 2 \mathrm{w} / \mathrm{v} \% \mathrm{NaOH}-\mathrm{CNF}, 7$ w/v $\% \mathrm{NaOH}-\mathrm{CNF}$, and $14 \mathrm{w} / \mathrm{v} \% \mathrm{NaOH}-\mathrm{CNF})$. This measurement was conducted on the surface of prepared nanopaper samples. The incorporated schematic describes the structural and compositional changes of CNF samples with controlled alkali treatment.

biochemical composition, FT-IR, and XPS studies (shown schematically in Figure 6)]. It is well known that these components reduce the material's wettability. ${ }^{15}$ Furthermore, by increasing the concentration of sodium hydroxide, the hydrophilicity of prepared CNF is steadily increased, such that $\theta$ for $14 \mathrm{w} / \mathrm{v} \% \mathrm{NaOH}-\mathrm{CNF}$ decreased to $\sim 43^{\circ}$.

Thermal Properties of CNF. The thermal decomposition behavior of the lignocellulosic material, as well as their composition, can be demonstrated by thermogravimetric analysis (TGA). Figure 7a,b shows the weight loss curve and

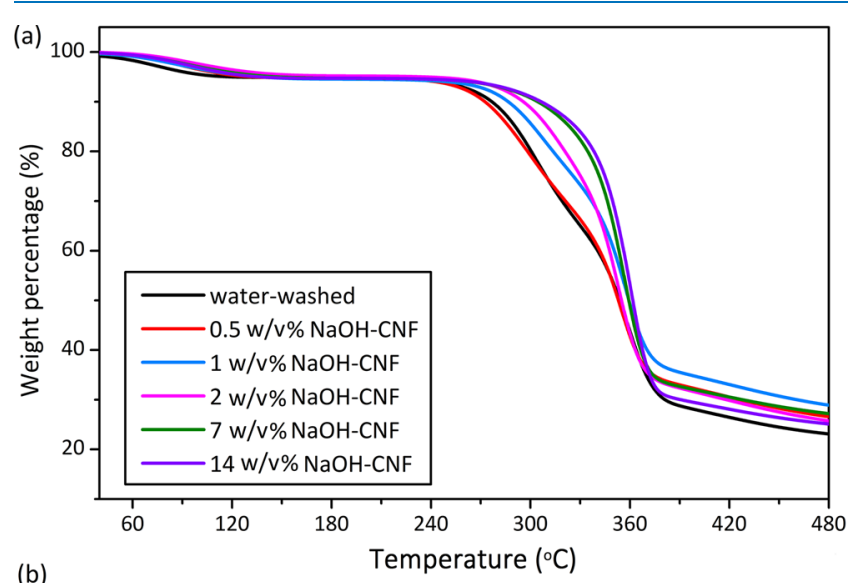

(b)

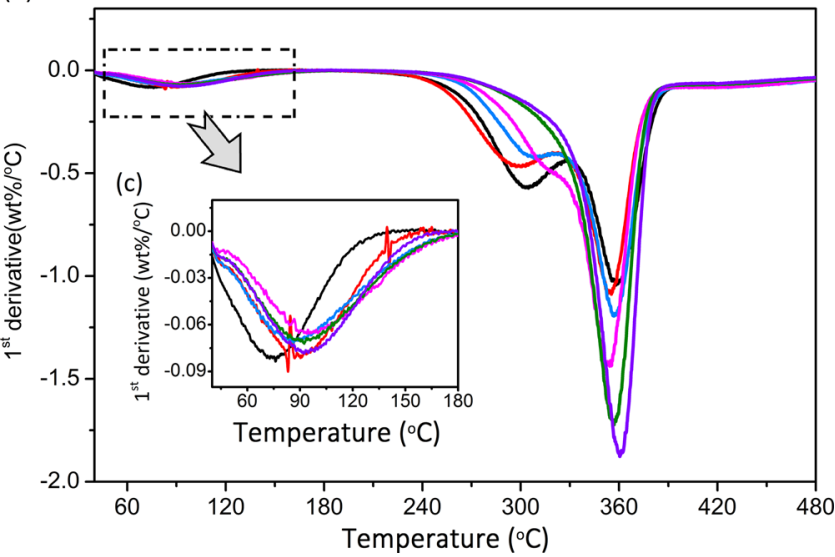

Figure 7. (a) TGA and (b) DTG patterns of water-washed and treated T. pungens $(0.5 \mathrm{w} / \mathrm{v} \% \mathrm{NaOH}-\mathrm{CNF}, 1 \mathrm{w} / \mathrm{v} \% \mathrm{NaOH}-\mathrm{CNF}$, $2 \mathrm{w} / \mathrm{v} \% \mathrm{NaOH}-\mathrm{CNF}, 7 \mathrm{w} / \mathrm{v} \% \mathrm{NaOH}-\mathrm{CNF}$, and $14 \mathrm{w} / \mathrm{v} \%$ $\mathrm{NaOH}-\mathrm{CNF}$ ) under a nitrogen flow. first derivative of the weight loss curves versus temperature [derivative thermogravimetric (DTG)] for water-washed and CNF samples between 40 and $500{ }^{\circ} \mathrm{C}$, respectively. These TGA curves consist of three main phases. In the first phase, starting at $40{ }^{\circ} \mathrm{C}$ and ending at $200{ }^{\circ} \mathrm{C}$, the initial weight loss in the samples was attributed to breakage of waterlignocellulosic bonds. ${ }^{56}$ The higher resolution of this phase is plotted in Figure $7 c$, and it can be seen that the moisture evaporation onset temperature for water-washed T. pungens is lower than the CNF samples. This indicates that water molecules are weakly bound with components in the waterwashed $T$. pungens, which consist of a higher content of hydrophobic components, such as lignin and resin. ${ }^{15}$

In the second phase, between 200 and $315^{\circ} \mathrm{C}$, amorphous structures such as hemicellulose (i.e., xylose, mannose, galactose, and glucose) become depolymerized. ${ }^{56,57}$ In addition, lignin degradation was initiated at this phase, but at a very low mass loss rate (less than $0.14 \mathrm{wt} \% /{ }^{\circ} \mathrm{C}$, based on the Yang et al. study), and lasted to a higher temperature (Yang et al. showed over $50 \mathrm{wt} \%$ of lignin remained over $\left.800{ }^{\circ} \mathrm{C}\right) .{ }^{57,58}$ The TGA and DTG curves in this phase showed water-washed $T$. pungens had lost the maximum mass among all samples, started decomposition at about $210{ }^{\circ} \mathrm{C}$, and exhibited a DTG peak at $303{ }^{\circ} \mathrm{C}$. It is expected that the thermal stability of samples is enhanced in the second phase by increasing the concentration of sodium hydroxide during alkali treatment because of the removal of hemicellulose and lignin. This phenomenon is obvious in Figure 7a,b, especially for 7 and 14 $\mathrm{w} / \mathrm{v} \% \mathrm{NaOH}-\mathrm{CNF}$ samples. As these samples (7 and $14 \mathrm{w} / \mathrm{v}$ $\% \mathrm{NaOH}-\mathrm{CNF}$ ) contain less hemicellulose in their biochemical composition (Figure 1), no peak can be distinguished in the second phase of the DTG curve (Figure 7b).

The last phase of TGA took place after $315{ }^{\circ} \mathrm{C}$, which corresponds to cellulose decomposition and main degradation steps accrue in this stage. The TGA curves show the onset degradation temperature $\left(T_{\text {onset }}\right)$ occurred at a higher temperature for samples treated with concentrated sodium hydroxide. Furthermore, the DTG curves that show the maximal weight loss temperature $\left(T_{\max }\right)$ for all samples are within the same range, between 354 and $361{ }^{\circ} \mathrm{C}$, but the rate of cellulose degradation is fairly inconsistent with respect to the sodium hydroxide concentration for alkali treatment. It can be seen that the first derivative of the weight loss ( $\mathrm{dTGA} / \mathrm{dT})$ for water-washed $T$. pungens took place at $-1.01 \mathrm{wt} \% /{ }^{\circ} \mathrm{C}$ and increased to $-1.85 \mathrm{wt} \% /{ }^{\circ} \mathrm{C}$ for $14 \mathrm{w} / \mathrm{v} \% \mathrm{NaOH}-\mathrm{CNF}$. The residual masses at $500{ }^{\circ} \mathrm{C}$ were almost identical for all samples, between 22 and $28 \mathrm{wt} \%$. Overall, all of these results indicated that the thermal stability of CNF was enhanced by increasing the concentration of sodium hydroxide during treatment. This phenomenon can be explained by two factors. First, concentrated sodium hydroxide removes more hemicellulose and lignin during alkali treatment. Second, as discussed in XRD and solid-state NMR studies, samples prepared with a higher sodium hydroxide concentration consisted of a higher degree of ordered crystalline regions (less amount of polymeric disorder or amorphous structure). It is well known that this higher degree of crystallinity has a predictable impact on the thermal stability of the material, as a higher temperature and energy is necessary for degradation. ${ }^{56,59}$

Compatibilization and Reinforcement Effect in NR. To demonstrate the functionality of this method for preparing $\mathrm{CNF}$ with desired properties, a series of CNF samples were used to reinforce prevulcanized NR latex. Several CNF/NR 
nanocomposites were prepared with various CNF types (0.5 $\mathrm{w} / \mathrm{v} \% \mathrm{NaOH}$ to $14 \mathrm{w} / \mathrm{v} \% \mathrm{NaOH}$ ) and different CNF loadings $(0.1,0.3,0.6$, and 1 wt $\%)$. To determine the reinforcement efficiency of $\mathrm{CNF}$ in the NR matrix, uniaxial tensile tests were performed on the film samples, and the ultimate tensile stress and elongation at break results are plotted in Figure 8. Furthermore, Figure S7a shows the stress

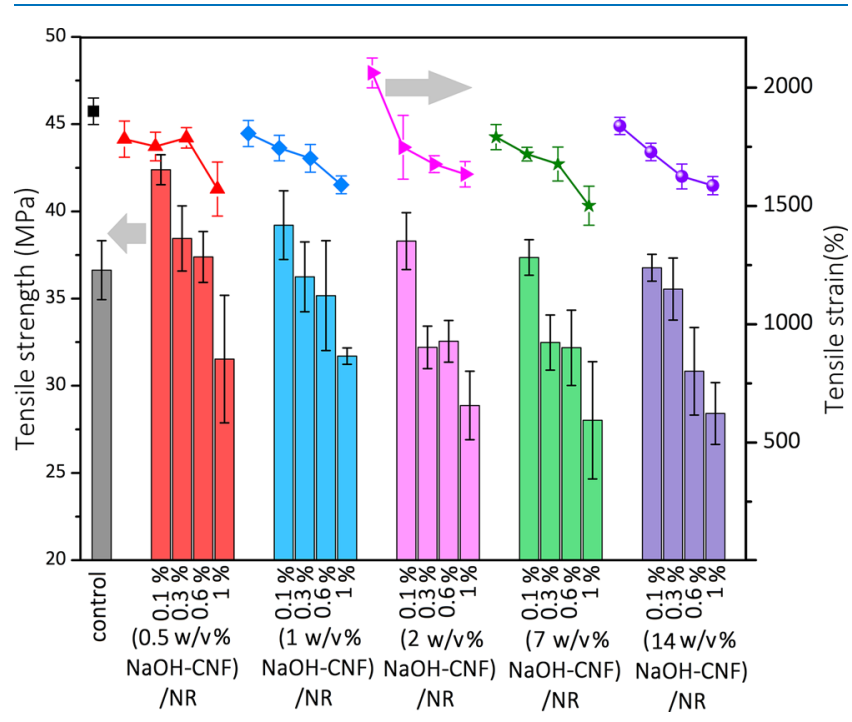

Figure 8. Mechanical properties [tensile stress (left axis) and tensile strain (right axis)] of the control NR and CNF/NR nanocomposites with different alkali treatment types $(0.5-14 \mathrm{w} / \mathrm{v} \%)$ and various CNF loading concentrations $(0.1-1 \mathrm{wt} \%)$.

at 300 and $700 \%$ elongation, and Figure S7b shows the toughness value (integration of the typical stress-strain curve) of the nanocomposite samples.

The control sample exhibited $36.6 \mathrm{MPa}$ and $1900 \%$ for tensile stress and elongation at break, respectively, indicating a very high-quality commercial latex control. Moreover, the toughness value for the control sample was $181 \mathrm{MJ} \mathrm{m}^{-3}$. The tensile strength of the CNF/NR samples with $0.1 \mathrm{wt} \% \mathrm{CNF}$ loading increased in comparison with the control sample across the board, regardless of CNF type; although, the degree of tensile strength increase varied based on the CNF type. The tensile strength of $0.1 \mathrm{wt} \%(0.5 \mathrm{w} / \mathrm{v} \% \mathrm{NaOH}-\mathrm{CNF}) / \mathrm{NR}$ improved by $16 \%$ (to $42.4 \mathrm{MPa}$ ) is relative to the control sample, whereas the degree of tensile strength enhancement decreased with increasing the concentration of employed sodium hydroxide. The tensile strength of $0.1 \mathrm{wt} \%(14 \mathrm{w} / \mathrm{v} \%$ $\mathrm{NaOH}-\mathrm{CNF}$ )/NR was almost the same as the control sample, at $36.7 \mathrm{MPa}(0.3 \%$ improvement). It is well known that excellent nanofiller dispersion, alongside proper adhesion and interface/interconnection between nanofillers, and between the nanofiller and the matrix, are the keys to achieving reinforcement in polymer nanocomposites. ${ }^{60}$ The very mild 0.5 $\mathrm{w} / \mathrm{v} \% \mathrm{NaOH}$-treated CNF was composed of more hydrophobic surface functionality (Figure 6) compared to the $14 \mathrm{w} /$ $\mathrm{v} \% \mathrm{NaOH}-\mathrm{CNF}$, which is due to the presence of more lignin and hemicellulose, as discussed in previous sections. Therefore, it was expected that better dispersion and interfacial compatibility might be achieved between the hydrophobic NR matrix and the most hydrophobic CNF filler $(0.5 \mathrm{w} / \mathrm{v} \%$ $\mathrm{NaOH}-\mathrm{CNF}$ sample), compared to the $14 \mathrm{w} / \mathrm{v} \% \mathrm{NaOH}-$ CNF sample. It was found that these nanofibers, at a low loading concentration ( $0.1 \mathrm{wt} \%)$, can improve reinforcement with NR and without significantly impacting the elongation at break (tensile strain) of the nanocomposite films. It can be seen that the tensile strain only decreased $6 \%$ for $0.1 \mathrm{wt} \%(0.5$ $\mathrm{w} / \mathrm{v} \% \mathrm{NaOH}-\mathrm{CNF}) / \mathrm{NR}$, but the tensile strain increased $8 \%$ for 0.1 wt $\%(2 \mathrm{w} / \mathrm{v} \% \mathrm{NaOH}-\mathrm{CNF}) / \mathrm{NR}$. This can be attributed to the average diameter size of $2 \mathrm{w} / \mathrm{v} \% \mathrm{NaOH}-$ CNF $(14.8 \mathrm{~nm})$, which exhibited the thinnest nanofibers among all CNF samples in the series, as shown in the TEM study (Figure 2). Larger CNF bundles could certainly act as stress raisers and limit the ductility of the nanocomposite latex films.

Accordingly, it can be seen in Figure 8 that the tensile stress and tensile strain of $\mathrm{CNF} / \mathrm{NR}$ nanocomposites decreased when increasing the loading concentration of CNF for all CNF types. This phenomenon is attributed to the agglomeration of $\mathrm{CNF}$ at higher loading (exaggerated by the high aspect ratio of CNF from spinifex sources), resulting in inferior mechanical performance, as reported in previous studies. ${ }^{18,28,61}$ In addition, although the semi cross-linked prevulcanized NR latex was drying, the microscale globules of latex coalesce and limit the interstitial space available for CNF accumulation. ${ }^{62}$ Thus, this degree of $\mathrm{CNF}$ agglomeration strongly influences the mechanical performance of $\mathrm{CNF} / \mathrm{NR}$ nanocomposites, as the difference in Young's modulus between the nanofiller and host polymer is usually the instigator of cracking in these systems.

To fabricate high-quality NR nanocomposites for applications such as gloves and condoms, it is necessary to increase the toughness of the nanocomposites without compromising compliance. Figure S7a shows the stress at 300 and $700 \%$ strain as a factor of stiffness for the prepared NR nanocomposite films. The stress at these elongations was slightly increased with respect to increasing CNF concentration, indicating that nanocomposite preparation at low CNF loadings ( 0.1 and $0.3 \mathrm{wt} \%)$ can reinforce latex without significantly impacting film stiffness. Furthermore, the toughness value for all samples is plotted in Figure S7b. The toughness values for $0.1 \mathrm{wt} \%(0.5 \mathrm{w} / \mathrm{v} \% \mathrm{CNF}-\mathrm{NaOH}) / \mathrm{NR}$ and $0.1 \mathrm{wt} \%(1 \mathrm{w} / \mathrm{v} \% \mathrm{CNF}-\mathrm{NaOH}) / \mathrm{NR}$ films were found to increase by 9 and $6 \%$ compared to the control sample, respectively. With respect to the observed increase in the elongation at break for the $0.1 \mathrm{wt} \%(2 \mathrm{w} / \mathrm{v} \% \mathrm{CNF}-\mathrm{NaOH}) /$ NR film, the toughness was also enhanced by $19 \%$ (215.6 MJ $\left.\mathrm{m}^{-3}\right)$. Toughness values were very similar to the control sample for 0.1 wt $\%(7 \mathrm{w} / \mathrm{v} \% \mathrm{CNF}-\mathrm{NaOH}) / \mathrm{NR}, 0.1 \mathrm{wt} \%$ $(14 \mathrm{w} / \mathrm{v} \% \mathrm{CNF}-\mathrm{NaOH}) / \mathrm{NR}$, and $0.3 \mathrm{wt} \%(0.5 \mathrm{w} / \mathrm{v} \%$ $\mathrm{CNF}-\mathrm{NaOH} / \mathrm{NR}$. By increasing the CNF loading from 0.1 to 1 wt $\%$ and increasing the concentration of sodium hydroxide from 0.5 to $14 \mathrm{w} / \mathrm{v} \%$ during the alkali treatment, the toughness value of NR nanocomposite films was decreased.

\section{CONCLUSIONS}

In this work, an efficient, inexpensive, and environmentally friendly treatment process was proposed to isolate a series of CNFs from $T$. pungens spinifex grass with distinct composition and surface chemistry. This treatment process involved analyzing the effect of different sodium hydroxide concentrations in cellulose nanofibrillation. Comprehensive characterization tools demonstrated that CNF properties and performance could be tuned by controlling the concentration of sodium hydroxide during treatment. It was concluded that sodium hydroxide has a significant effect on the size, surface 
tension, degree of residual lignin and hemicellulose, and the crystallinity of isolated CNF. The tensile strength of industrial grade prevulcanized NR latex was enhanced by $16 \%$ with the incorporation of $0.1 \mathrm{wt} \% \mathrm{CNF}$ (at $0.5 \mathrm{w} / \mathrm{v} \% \mathrm{NaOH}$ ), whereas the toughness increased and the tensile strain was not significantly affected. On the basis of the current experiment, this fibrillation strategy is an efficient and practical approach for obtaining CNF with tuned interfacial chemistry, highlighting this process' potential of handling large-scale production for many different applications.

\section{EXPERIMENTAL SECTION}

Preparation of CNF. Preparation of CNF consisted of two steps: controlled alkali treatment and high shear disintegration via $\mathrm{HPH}$. Overnight deionized (DI) water soaked T. pungens (grass to water ratio of $1: 10$ ) was heated to $80{ }^{\circ} \mathrm{C}$ and treated with various sodium hydroxide concentrations $(0.5,1,2,7$, and $14 \mathrm{w} / \mathrm{v} \%)$, such that alkali treating of $10 \mathrm{~g}$ of $T$. pungens at 0.5 $\mathrm{w} / \mathrm{v} \% \mathrm{NaOH}$ would require $0.5 \mathrm{~g}$ of sodium hydroxide and $100 \mathrm{~mL}$ of DI water. After being stirred for $2 \mathrm{~h}$, alkali-treated pulp was obtained by filtering and washing several times with $60{ }^{\circ} \mathrm{C}$ water. Then, the pulp was diluted with DI water to a concentration of approximately $3-4 \mathrm{mg} \mathrm{mL}^{-1}$ and fibrillated by passing through a high-pressure homogenizer (GEA homogenizer, Panda 2K NS1001L, GEA Niro Soavi S.P.A., Italy) once at a pressure of 400 bar and 4 passes at a pressure of 700 bar.

Preparation of Control NR and CNF/NR Nanocomposite Samples. Prevulcanized NR latex was used to prepare control and CNF/NR nanocomposite films. After overhead stirring at a speed of $35 \mathrm{rpm}$ for $30 \mathrm{~min}$, the solid content of the NR latex was reduced from 60 to $45 \mathrm{wt} \%$ with an aqueous ammonia alkali solution at $\mathrm{pH}=10.5$ (for the latex control), or a dispersed CNF aqueous alkali solution $(\mathrm{pH}=$ 10.5 ) with different CNF concentrations of $0.1,0.3,0.6$, and 1 wt \% (for nanocomposite latex preparations). Stirring was continued for $1 \mathrm{~h}$ at $35 \mathrm{rpm}$, then for $24 \mathrm{~h}$ at $12 \mathrm{rpm}$ to complete CNF dispersion and deaeration. Prepared mixtures were cast into glass molds and kept at room temperature overnight to form dry films. Dried films were then dusted with calcium carbonate powder (to prevent films' tackiness) and leached with hot water $\left(65^{\circ} \mathrm{C}\right)$ for $10 \mathrm{~min}$. Vulcanization was performed by curing samples at $110^{\circ} \mathrm{C}$ for $6 \mathrm{~h}$ under a gentle flow of dry nitrogen. All samples were rested for at least $48 \mathrm{~h}$ within laboratory conditions (room temperature and 50\% humidity) before further characterization. Samples were labeled according to their CNF concentration and alkali treatment regimen.

\section{ASSOCIATED CONTENT}

\section{S Supporting Information}

The Supporting Information is available free of charge on the ACS Publications website at DOI: 10.1021/acsomega.8b02104.

It contains experimental details and FT-IR, SEM, XPS, ${ }^{13} \mathrm{C}$ solid-state $\mathrm{NMR}$, and mechanical properties data of the samples (PDF)

\section{AUTHOR INFORMATION}

\section{Corresponding Authors}

*E-mail: darren.martin@uq.edu.au (D.J.M.).

*E-mail: n.amiralian@uq.edu.au (N.A.).

\section{ORCID}

Alireza Hosseinmardi: 0000-0001-7665-7197

Pratheep Kumar Annamalai: 0000-0002-7284-0813

Nasim Amiralian: 0000-0003-2624-2561

\section{Notes}

The authors declare no competing financial interest.

\section{ACKNOWLEDGMENTS}

The authors gratefully acknowledge the Australian government for an international postgraduate research scholarship (IPRS), the University of Queensland living allowance scholarship, and University of Queensland continental scholarship. Thanks to the Synthomer Revertex Company in Malaysia for the provision of the prevulcanized NR latex sample. The authors would like to thank the staff in the Australian Microscopy and Microanalysis Research Facility at the Centre for Microscopy and Microanalysis (CMM, UQ), the University of Queensland, and special thanks to Dr. Barry Wood for taking XPS spectra. In addition, they would like to thank Dr. Ekaterina Strounina for taking solid-state NMR spectra at the Centre of Advanced Imaging (CAI, The University of Queensland). P.K.A. and N.A. thank the Queensland Government for the Advance Queensland Research Fellowships. The authors are thankful to the Dugalunji Aboriginal Corporation (DAC) for supporting the research through Federal Indigenous Advancement Strategy (IAS) funding, sourcing the spinifex grass used in this study and other in-kind support. The authors also acknowledge that any commercial proceeds resulting from the spinifex research are shared between the University of Queensland and DAC in accordance with the Spinifex Umbrella Research Agreement (SURA).

\section{REFERENCES}

(1) Zhu, M.; Lan, J.; Tan, C.; Sui, G.; Yang, X. Degradable cellulose acetate/poly-l-lactic acid/halloysite nanotube composite nanofiber membranes with outstanding performance for gel polymer electrolytes. J. Mater. Chem. A 2016, 4, 12136-12143.

(2) Rojo, E.; Peresin, M. S.; Sampson, W. W.; Hoeger, I. C.; Vartiainen, J.; Laine, J.; Rojas, O. J. Comprehensive elucidation of the effect of residual lignin on the physical, barrier, mechanical and surface properties of nanocellulose films. Green Chem. 2015, 17, $1853-1866$.

(3) Desmaisons, J.; Boutonnet, E.; Rueff, M.; Dufresne, A.; Bras, J. A new quality index for benchmarking of different cellulose nanofibrils. Carbohydr. Polym. 2017, 174, 318-329.

(4) Pérez-Madrigal, M. M.; Edo, M. G.; Alemán, C. Powering the future: application of cellulose-based materials for supercapacitors. Green Chem. 2016, 18, 5930-5956.

(5) Ling, Z.; Chen, S.; Zhang, X.; Takabe, K.; Xu, F. Unraveling variations of crystalline cellulose induced by ionic liquid and their effects on enzymatic hydrolysis. Sci. Rep. 2017, 7, 10230.

(6) Larsson, P. A.; Wågberg, L. Towards natural-fibre-based thermoplastic films produced by conventional papermaking. Green Chem. 2016, 18, 3324-3333.

(7) Alonso, D. M.; Wettstein, S. G.; Mellmer, M. A.; Gurbuz, E. I.; Dumesic, J. A. Integrated conversion of hemicellulose and cellulose from lignocellulosic biomass. Energy Environ. Sci. 2013, 6, 76-80.

(8) Spence, K. L.; Venditti, R. A.; Rojas, O. J.; Habibi, Y.; Pawlak, J. $\mathrm{J}$. A comparative study of energy consumption and physical properties of microfibrillated cellulose produced by different processing methods. Cellulose 2011, 18, 1097-1111.

(9) Zhao, L.; Sun, X.; Liu, Q.; Zhao, J.; Xing, W. Natural Rubber/ Graphene Oxide Nanocomposites Prepared by Latex Mixing. J. Macromol. Sci., Part B: Phys. 2015, 54, 581-592. 
(10) Clough, M. T. Organic electrolyte solutions as versatile media for the dissolution and regeneration of cellulose. Green Chem. 2017, 19, 4754-4768.

(11) Barana, D.; Ali, S. D.; Salanti, A.; Orlandi, M.; Castellani, L.; Hanel, T.; Zoia, L. Influence of lignin features on thermal stability and mechanical properties of natural rubber compounds. ACS Sustain. Chem. Eng. 2016, 4, 5258-5267.

(12) Li, X.; Tabil, L. G.; Panigrahi, S. Chemical treatments of natural fiber for use in natural fiber-reinforced composites: a review. J. Polym. Environ. 2007, 15, 25-33.

(13) Liu, W.; Mohanty, A. K.; Drzal, L. T.; Askel, P.; Misra, M. Effects of alkali treatment on the structure, morphology and thermal properties of native grass fibers as reinforcements for polymer matrix composites. J. Mater. Sci. 2004, 39, 1051-1054.

(14) Cai, M.; Takagi, H.; Nakagaito, A. N.; Li, Y.; Waterhouse, G. I. $\mathrm{N}$. Effect of alkali treatment on interfacial bonding in abaca fiberreinforced composites. Composites, Part A 2016, 90, 589-597.

(15) Chinga-Carrasco, G.; Kuznetsova, N.; Garaeva, M.; Leirset, I.; Galiullina, G.; Kostochko, A.; Syverud, K. Bleached and unbleached MFC nanobarriers: properties and hydrophobisation with hexamethyldisilazane. J. Nanopart. Res. 2012, 14, 1280.

(16) Teli, M. D.; Terega, J. M. Effects of alkalization on the properties of ensete ventricosum plant fibre. J. Text. Inst. 2018, 1-12.

(17) Amiralian, N.; Annamalai, P. K.; Memmott, P.; Martin, D. J. Isolation of cellulose nanofibrils from Triodia Pungens via different mechanical methods. Cellulose 2015, 22, 2483-2498.

(18) Hosseinmardi, A.; Annamalai, P. K.; Wang, L.; Martin, D.; Amiralian, N. Reinforcement of natural rubber latex using lignocellulosic nanofibers isolated from spinifex grass. Nanoscale 2017, 9, 9510-9519.

(19) Abbate Dos Santos, F.; Iulianelli, G. C. V.; Tavares, M. I. B. The use of cellulose nanofillers in obtaining polymer nanocomposites: properties, processing, and applications. Mater. Sci. Appl. 2016, 7, 257.

(20) Cherian, B. M.; Leão, A. L.; de Souza, S. F.; Thomas, S.; Pothan, L. A.; Kottaisamy, M. Isolation of nanocellulose from pineapple leaf fibres by steam explosion. Carbohydr. Polym. 2010, 81, $720-725$.

(21) Singh, S.; Simmons, B. A.; Vogel, K. P. Visualization of biomass solubilization and cellulose regeneration during ionic liquid pretreatment of switchgrass. Biotechnol. Bioeng. 2009, 104, 68-75.

(22) Samuel, R.; Foston, M.; Jiang, N.; Allison, L.; Ragauskas, A. J. Structural changes in switchgrass lignin and hemicelluloses during pretreatments by NMR analysis. Polym. Degrad. Stabil. 2011, 96, 2002-2009.

(23) Zhu, Z.; Sathitsuksanoh, N.; Vinzant, T.; Schell, D. J.; McMillan, J. D.; Zhang, Y.-H. P. Comparative study of corn stover pretreated by dilute acid and cellulose solvent-based lignocellulose fractionation: Enzymatic hydrolysis, supramolecular structure, and substrate accessibility. Biotechnol. Bioeng. 2009, 103, 715-724.

(24) Leão, R. M.; Miléo, P. C.; Maia, J. M. L. L.; Luz, S. M. Environmental and technical feasibility of cellulose nanocrystal manufacturing from sugarcane bagasse. Carbohydr. Polym. 2017, $175,518-529$.

(25) Tang, S.; Baker, G. A.; Ravula, S.; Jones, J. E.; Zhao, H. PEGfunctionalized ionic liquids for cellulose dissolution and saccharification. Green Chem. 2012, 14, 2922-2932.

(26) Kargarzadeh, H.; Ahmad, I.; Abdullah, I.; Dufresne, A.; Zainudin, S. Y.; Sheltami, R. M. Effects of hydrolysis conditions on the morphology, crystallinity, and thermal stability of cellulose nanocrystals extracted from kenaf bast fibers. Cellulose 2012, 19, $855-866$.

(27) Zhao, Y.; Zhang, Y.; Lindström, M. E.; Li, J. Tunicate cellulose nanocrystals: Preparation, neat films and nanocomposite films with glucomannans. Carbohydr. Polym. 2015, 117, 286-296.

(28) Amiralian, N.; Annamalai, P. K.; Memmott, P.; Taran, E.; Schmidt, S.; Martin, D. J. Easily deconstructed, high aspect ratio cellulose nanofibres from Triodia Pungens; an abundant grass of Australia's arid zone. RSC Adv. 2015, 5, 32124-32132.
(29) da Costa Lopes, A. M.; João, K. G.; Rubik, D. F.; Bogel-Łukasik, E.; Duarte, L. C.; Andreaus, J.; Bogel-Łukasik, R. Pre-treatment of lignocellulosic biomass using ionic liquids: Wheat straw fractionation. Bioresour. Technol. 2013, 142, 198-208.

(30) Sun, X.-F.; Jing, Z.; Fowler, P.; Wu, Y.; Rajaratnam, M. Structural characterization and isolation of lignin and hemicelluloses from barley straw. Ind. Crops Prod. 2011, 33, 588-598.

(31) Fan, M.; Dai, D.; Huang, B. Fourier transform infrared spectroscopy for natural fibres. In Fourier Transform-Materials Analysis; Salih, S. M., Ed.; InTech, 2012; Vol. 1, pp 45-68.

(32) Popescu, C.-M.; Popescu, M.-C.; Singurel, G.; Vasile, C.; Argyropoulos, D. S.; Willfor, S. Spectral characterization of Eucalyptus wood. Appl. Spectrosc. 2007, 61, 1168-1177.

(33) Zidan, Y.; El Hadidi, N. M.; Mohamed, M. F. Examination and analyses of a wooden face at the museum storage at the faculty of archaeology, Cairo University. Mediterr. Archaeol. Archaeometry 2016, $16,1-11$

(34) Wang, Q.; Wei, W.; Kingori, G. P.; Sun, J. Cell wall disruption in low temperature $\mathrm{NaOH} /$ urea solution and its potential application in lignocellulose pretreatment. Cellulose 2015, 22, 3559-3568.

(35) Simmons, T. J.; Mortimer, J. C.; Bernardinelli, O. D.; Pöppler, A.-C.; Brown, S. P.; deAzevedo, E. R.; Dupree, R.; Dupree, P. Folding of xylan onto cellulose fibrils in plant cell walls revealed by solid-state NMR. Nat. Commun. 2016, 7, 13902.

(36) Liu, C.-F.; Zhang, A.-P.; Li, W.-Y.; Yue, F.-X.; Sun, R.-C. Homogeneous Modification of Cellulose in Ionic Liquid with Succinic Anhydride UsingN-Bromosuccinimide as a Catalyst. J. Agric. Food Chem. 2009, 57, 1814-1820.

(37) Nishida, M.; Tanaka, T.; Miki, T.; Ito, T.; Kanayama, K. Multiscale instrumental analyses for structural changes in steam-treated bamboo using a combination of several solid-state NMR methods. Ind. Crops Prod. 2017, 103, 89-98.

(38) Sun, X. F.; Xu, F.; Sun, R. C.; Fowler, P.; Baird, M. S. Characteristics of degraded cellulose obtained from steam-exploded wheat straw. Carbohydr. Res. 2005, 340, 97-106.

(39) Komatsu, T.; Kikuchi, J. Comprehensive signal assignment of 13C-labeled lignocellulose using multidimensional solution NMR and 13C chemical shift comparison with solid-state NMR. Analytical Chim 2013, 85, 8857-8865.

(40) Foston, M. Advances in solid-state NMR of cellulose. Curr. Opin. Biotechnol. 2014, 27, 176-184.

(41) Holm Kristensen, J.; Bampos, N.; Duer, M. Solid state 13C CP MAS NMR study of molecular motions and interactions of urea adsorbed on cotton cellulose. Phys. Chem. Chem. Phys. 2004, 6, 31753183.

(42) Foston, M.; Katahira, R.; Gjersing, E.; Davis, M. F.; Ragauskas, A. J. Solid-state selective $13 \mathrm{C}$ excitation and spin diffusion NMR to resolve spatial dimensions in plant cell walls. J. Agric. Food Chem. 2012, 60, 1419-1427.

(43) Teleman, A.; Larsson, P. T.; Iversen, T. On the accessibility and structure of xylan in birch kraft pulp. Cellulose 2001, 8, 209-215.

(44) Synytsya, A.; Novak, M. Structural analysis of glucans. Ann. Transl. Med. 2014, 2, 17.

(45) Hansen, B.; Kusch, P.; Schulze, M.; Kamm, B. Qualitative and quantitative analysis of lignin produced from beech wood by different conditions of the organosolv process. J. Polym. Environ. 2016, 24, 8597.

(46) Grabber, J. H.; Ralph, J.; Hatfield, R. D.; Quideau, S. phydroxyphenyl, guaiacyl, and syringyl lignins have similar inhibitory effects on wall degradability. J. Agric. Food Chem. 1997, 45, 25302532.

(47) Hatcher, P. G. Chemical structural studies of natural lignin by dipolar dephasing solid-state $13 \mathrm{C}$ nuclear magnetic resonance. Org. Geochem. 1987, 11, 31-39.

(48) Fu, L.; McCallum, S. A.; Miao, J.; Hart, C.; Tudryn, G. J.; Zhang, F.; Linhardt, R. J. Rapid and accurate determination of the lignin content of lignocellulosic biomass by solid-state NMR. Fuel 2015, 141, 39-45. 
(49) Ma, J. F.; Tamai, K.; Yamaji, N.; Mitani, N.; Konishi, S.; Katsuhara, M.; Ishiguro, M.; Murata, Y.; Yano, M. A silicon transporter in rice. Nature 2006, 440, 688-691.

(50) Casey, W. H.; Kinrade, S. D.; Knight, C. T. G.; Rains, D. W.; Epstein, E. Aqueous silicate complexes in wheat, Triticum aestivum $\mathrm{L}$. Plant Cell Environ. 2004, 27, 51-54.

(51) Islam, M.; Adams, M. A. Mineral content and nutritive value of native grasses and the response to added phosphorus in a Pilbara rangeland. Trop. Grassl. 1999, 33, 193-200.

(52) Truss, R. W.; Wood, B.; Rasch, R. Quantitative surface analysis of hemp fibers using XPS, conventional and low voltage in-lens SEM. J. Appl. Polym. Sci. 2016, 133, 43023.

(53) Beamson, G.; Briggs, D. High Resolution XPS of Organic Polymers: The Scienta ESCA300 Database; Wiley, 1992.

(54) Johansson, L.-S.; Campbell, J. M.; Koljonen, K.; Stenius, P. Evaluation of surface lignin on cellulose fibers with XPS. Appl. Surf. Sci. 1999, 144, 92-95.

(55) Gustafsson, J.; Ciovica, L.; Peltonen, J. The ultrastructure of spruce Kraft pulps studied by atomic force microscopy (AFM) and Xray photoelectron spectroscopy (XPS). Polymer 2003, 44, 661-670.

(56) Sonia, A.; Priya Dasan, K. Chemical, morphology and thermal evaluation of cellulose microfibers obtained from Hibiscus sabdariffa. Carbohydr. Polym. 2013, 92, 668-674.

(57) Yang, H.; Yan, R.; Chen, H.; Lee, D. H.; Zheng, C. Characteristics of hemicellulose, cellulose and lignin pyrolysis. Fuel 2007, 86, 1781-1788.

(58) Bian, H.; Gao, Y.; Wang, R.; Liu, Z.; Wu, W.; Dai, H. Contribution of lignin to the surface structure and physical performance of cellulose nanofibrils film. Cellulose 2018, 25, 13091318.

(59) Jonoobi, M.; Harun, J.; Mishra, M.; Oksman, K. Chemical composition, crystallinity and thermal degradation of bleached and unbleached kenaf bast (Hibiscus cannabinus) pulp and nanofiber. BioResources 2009, 4, 626-639.

(60) Sapkota, J.; Gooneie, A.; Shirole, A.; Martinez Garcia, J. C. A refined model for the mechanical properties of polymer composites with nanorods having different length distributions. J. Appl. Polym. Sci. 2017, 134, 45279.

(61) Amiralian, N.; Annamalai, P. K.; Garvey, C. J.; Jiang, E.; Memmott, P.; Martin, D. J. High aspect ratio nanocellulose from an extremophile spinifex grass by controlled acid hydrolysis. Cellulose 2017, 24, 3753-3766.

(62) Wu, X.; Lu, C.; Zhang, X.; Zhou, Z. Conductive natural rubber/carbon black nanocomposites via cellulose nanowhisker templated assembly: tailored hierarchical structure leading to synergistic property enhancements. J. Mater. Chem. A 2015, 3, 13317-13323. 